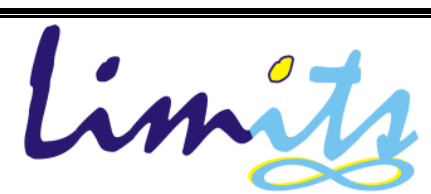

J. Math. and Its Appl.

E-ISSN: 2579-8936

P-ISSN: $1829-605 \mathrm{X}$

Vol. 15, No. 2, Nopember 2018, 89-96

\title{
Aplikasi Dimensi Metrik Untuk Meminimalkan Pemasangan Sensor Kebakaran Sebuah Gedung
}

\author{
Suhud Wahyudi \\ Departemen Matematika ITS Surabaya Indonesia \\ e-mail:suhud@matematika.its.ac.id
}

\begin{abstract}
Abstrak
Diberikan himpunan terurut $W=\left\{w_{1}, w_{2}, \cdots, w_{k}\right\} \subseteq V(G)$ dan untuk setiap vertex $v \in V(G)$ , representasi dari $v$ terhadap $W$ adalah $k$ - tuple $r(v \mid W)=\left(d\left(v, w_{1}\right), d\left(v, w_{2}\right), \cdots, d\left(v, w_{k}\right)\right)$, dimana $d(x, y)$ merepresentasikan jarak antara vertex $x$ dan $y$. Jika $r(v \mid W)$ untuk setiap vertex $v \in V(G)$ berbeda, maka $W$ disebut himpunan resolving dari $V(G)$. Himpunan resolving dengan kardinalitas minimum disebut himpunan resolving minimum, dan kardinalitas tersebut dinamakan dimensi metrik dari $G$ dinotasikan dengan $\operatorname{dim}(G)$.

Pada penelitian ini dibahas salah satu aplikasi dimensi metrik graf yaitu untuk meminimalkan pemasangan sensor kebakaran sebuah gedung. Dalam suatu gedung, ruangan dapat direpresentasikan sebagai vertex dan dinding atau lantai antara ruangan yang satu dengan lainnya sebagai edge dari suatu graf $G$ sehingga dapat dibuat graf terhubung yang mewakili gedung tersebut. Studi kasus yang diambil adalah sebuah gedung yang mempunyai 12 ruangan. Dari analisa yang dilakukan, sensor kebakaran yang harus dipasang di gedung hanya di tiga ruangan saja.
\end{abstract}

Kata kunci : himpunan resolving, kardinalitas minimum, dimensi metrik, sensor kebakaran.

\begin{abstract}
Given an ordered set $W=\left\{w_{1}, w_{2}, \cdots, w_{k}\right\} \subseteq V(G)$ and a vertex $v \in V(G)$, the representation of $v$ with respect to $W$ is the $\mathrm{k}$ - tuple $r(v \mid W)=\left(d\left(v, w_{1}\right), d\left(v, w_{2}\right), \cdots, d\left(v, w_{k}\right)\right)$, where $d(x, y)$ represents the distance between the vertexs $x$ and $y$. If $r(v \mid W)$ have distinct representations, then $W$ is called the resoving set of $V(G)$. The resolving set with minimum cardinality is called minimum resolving set, and the cardinality is called the metric dimension of $G$ denoted by $\operatorname{dim}(G)$

In the research we examine one application of the metric dimension of graph that is to minimize the installation of a fire sensor in a building. In a building, rooms building can be interpreted as a vertex and a wall or floor associated with the room interpreted as an edge wich connecting the vertexs. Case study is taken in building wich has 12 rooms. From the analysis carried out, the sensor should be installed in the building just in three rooms only.

Keyword : resolving set, minimum cardinality, metric dimension, fire sensor.
\end{abstract}

\section{Pendahuluan}

Teori graf pertama kali diperkenalkan oleh Leonhard Euler pada tahun 1736 ketika mendiskusikan tentang persoalan yang terjadi di kota Kaliningrad Rusia, yaitu bagaimana caranya agar seseorang dapat menyeberang ke semua jembatan tanpa harus melewati satu 
jembatan lebih dari satu kali. Publikasi dari masalah ini dan usulan solusinya dikenal sebagai masalah dari teori graf. Sejak saat itu, teori graf terus berkembang seiring dengan penemuanpenemuan baru yang terkait dengan graf. Saat ini teori graf telah dapat memberikan kerangka dasar bagi banyak persoalan yang berhubungan dengan struktur dan hubungan antara suatu obyek diskrit dalam bentuk apapun. Pemakaian teori graf telah dapat diterapkan dalam berbagai cabang ilmu pengetahuan seperti ilmu komputer, ekonomi, psikologi, ilmu sosial, genetika, riset operasional. Misalnya pada [1] menggunakan graf untuk memodelkan kompetisi antar spesies yang berbeda pada suatu ekologi lingkungan, dengan menganalisa siapa yang mempengaruhi atau siapa yang berada pada himpunan kelas yang sama, [2] menggunakan graf untuk mengilustrasikan jaringan lalu lintas, dan lain lain. Pada paper ini diaplikasikan konsep dimensi metrik graf tersebut untuk meminimumkan jumlah pemasangan sensor kebakaran pada suatu gedung.

Belum diketahui secara spesifik kapan bahasan dimensi partisi ini pertama kali ada. Ide dimensi metrik muncul dari himpunan resolving (dan himpunan resolving minimum) yang diperkenalkan oleh Slater [3] pada tahun 1975. Slater mengutarakan konsep himpunan locating untuk menyatakan himpunan resolving seperti yang dikenal saat ini. Ia menyatakan kardinalitas minimum himpunan resolving graf $G$ sebagai location number dinotasikan dengan loc $(G)$. Kemudian Melter dan Harary [4] pada tahun 1976 mengutarakan konsep dimensi metrik suatu graf seperti yang dikenal saat ini. Dimensi metrik adalah kardinalitas minimum dari himpunan resolving. Sampai saat ini, dimensi metrik terus dipelajari dan dikembangkan diantaranya oleh $G$. Cartrand [5] yang mendapatkan hasil bahwa untuk graf terhubung $G$ dengan orde $n \geq 2$ maka $\operatorname{dim}(G)=1$ jika dan hanya jika $G=P_{n}$, Rinurwati dkk.[6] membahas dimensi metrik dan dimensi metrik lokal dari graf yang memiliki $m$ - pendant, Suhud Wahyudi dkk.[7] membahas dimensi metrik Pengembangan Graf Kincir Pola $\mathrm{K}_{1}+\mathrm{mK}_{3}$, dan lain lain.

Misalkan $G(V, E)$ adalah graf tak berarah dan terhubung dengan $(V, \mathrm{E})$ berturut - turut menunjukkan (banyaknya vertex, banyaknya edge) di $G$, dan $u, v \in V$, jarak antara dua vertex $u$ dan $v$ di $G, d(u, v)$ didefinisikan sebagai panjang lintasan terpendek diantara keduanya. Untuk himpunan terurut $W=\left\{w_{1}, w_{2}, \cdots, w_{k}\right\}$ dari vertex-vertex dalam graf terhubung $G$ dan untuk setiap vertex $v \in V(G)$, representasi dari $v$ terhadap $W$ adalah $k$-tuple

$$
r(v \mid W)=\left(d\left(v, w_{1}\right), d\left(v, w_{2}\right), \cdots, d\left(v, w_{k}\right)\right) .
$$

Jika $r(v \mid W)$ untuk setiap vertex $v \in V(G)$ berbeda, maka $W$ disebut himpunan resolving dari $V(G)$. Himpunan resolving dengan kardinalitas minimum disebut himpunan resolving minimum, dan kardinalitas tersebut dinamakan dimensi metrik dari $G$ dinotasikan dengan $\operatorname{dim}(G)[8]$. 
[4] menunjukkan bahwa untuk setiap pasangan integer $\mathrm{n}$, $\mathrm{k}$ dengan $1 \leq \mathrm{k} \leq \mathrm{n}-1$, terdapat suatu graf dimensi k orde $\mathrm{n}$. Kemudian [5] menunjukkan bahwa selain graf path $\mathrm{P}_{\mathrm{n}}$, dimensi metriknya minimal 2.

Contoh berikut diberikan untuk memberikan gambaran mendapatkan himpunan resolving, himpunan resolving minimum dan dimensi metrik dari sebuah graf terhubung.

Diberikan graf terhubung $G$ dengan 5 vertex dan 6 edge seperti ditunjukkan pada Gambar 1, dan akan ditentukan himpunan resolving dari graf $G$ tersebut.

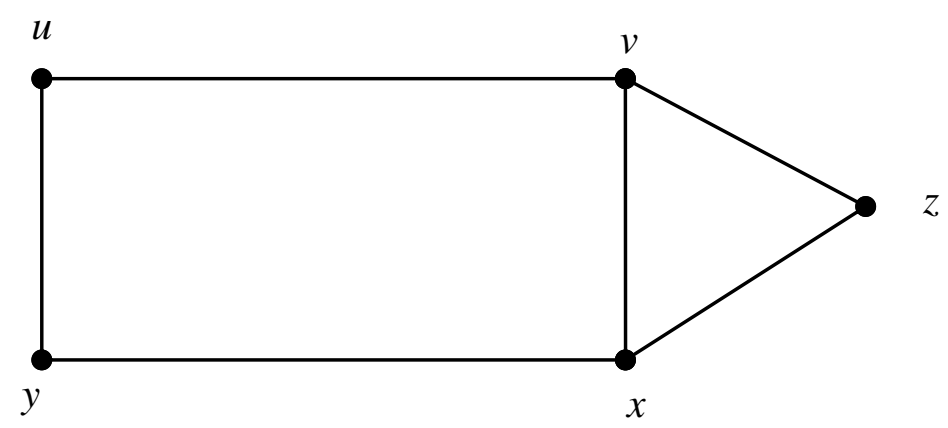

Gambar 1 Graf terhubung dengan 5 vertex dan 6 edge

Pembahasan :

Misalkan $W_{1}=(u)$. Representasi vertex-vertex di graf $G$ terhadap $W_{1}$ adalah $r\left(u \mid W_{1}\right)=(0)$, $r\left(v \mid W_{1}\right)=(1), r\left(y \mid W_{1}\right)=(1), r\left(x \mid W_{1}\right)=(2), r\left(z \mid W_{1}\right)=(2)$.

Karena $r\left(v \mid W_{1}\right)=r\left(y \mid W_{1}\right)=1$ dan $r\left(x \mid W_{1}\right)=r\left(z \mid W_{1}\right)=2$ maka $W_{1}$ bukan himpunan resolving dari graf $G$. Kemudian misalkan $W_{2}=\{u, v, y\}$. Maka representasi vertex-vertex di graf $\mathrm{G}$ terhadap $W_{2}$ adalah $r\left(u \mid W_{2}\right)=(0,1,1), \quad r\left(v \mid W_{2}\right)=(1,0,2), \quad r\left(y \mid W_{2}\right)=(1,2,0), \quad r\left(x \mid W_{2}\right)=(2,1,1)$, $r\left(z \mid W_{2}\right)=(2,1,2)$. Karena representasi vertex-vertex di graf $G$ terhadap $W_{2}$ berbeda, maka $W_{2}$ adalah himpunan resolving dari $G$. Akan tetapi $W_{2}$ bukan himpunan resolving minimum dari $V(G)$, karena $W_{3}$ berikut mempunyai kardinalitas lebih kecil dari $W_{2}$. Misalkan $W_{3}=\{u, y\}$. Maka representasi vertex-vertex di graf $G$ terhadap $W_{3}$ adalah $r\left(u \mid W_{3}\right)=(0,1), r\left(v \mid W_{3}\right)=(1,2)$, $r\left(z \mid W_{3}\right)=(2,2), \quad r\left(y \mid W_{3}\right)=(1,0) \quad r\left(x \mid W_{3}\right)=(2,1)$. Karena representasi vertex-vertex di graf $G$ terhadap $W_{3}$ berbeda, maka $W_{3}$ adalah himpunan resolving dari $V(G) . W_{3}$ adalah himpunan resolving minimum dari $V(G)$ karena tidak ada lagi himpunan resolving yang kardinalitasnya lebih kecil dari 2. Jadi graf diatas mempunyai dimensi 2 atau $\operatorname{dim}(G)=2$.

\section{Metode Penelitian}


Penelitian ini bertujuan untuk mengembangkan aplikasi teori graf. Dalam hal ini adalah dimensi metrik graf yang di aplikasikan untuk meminimumkan banyaknya sensor kebakaran yang harus di pasang dalam sutu gedung. Dimensi metrik graf yang dimaksud disini adalah dimensi metrik dari graf yang terhubung.

Dalam pengerjaan penelitian ini, pertama kali dilakukan analisa dimensi metrik graf secara umum, kemudian mengkonstruksi graf yang sesuai untuk sebuah gedung yang diberikan. Dari graf yang terbentuk tersebut ditentukan himpunan resolving dan dimensi metriknya.

\section{Hasil dan Pembahasan}

Dalam suatu gedung, ruangan dapat direpresentasikan sebagai vertex dan dinding atau lantai antara ruangan yang satu dengan lainnya sebagai edge dari suatu graf $G$ sehingga dapat dibuat graf terhubung yang mewakili gedung tersebut. Dalam hal ini dimensi metrik dari graf sebuah gedung yang diperoleh dari himpunan resolving minimum dapat digunakan sebagai dasar untuk meminimalkan pemasangan sensor kebakaran sebuah gedung. Dengan memilih salah satu dari himpunan resolving minimum dapat ditentukan ruangan mana saja yang harus diberi sensor untuk mendeteksi asal adanya api sehingga dapat meminimalkan pemasangan sensor kebakaran sebuah gedung.

Misalkan sebuah gedung yang memiliki 12 ruangan dengan masing-masing ruang diberi label nama $R_{1}, R_{2}, R_{3}, R_{4}, R_{5}, R_{6}, R_{7}, R_{8}, R_{9}, R_{10}, R_{11}, R_{12}$ dengan hubungan antara ruang satu dengan yang lainnya seperti ditunjukkan pada Gambar 2. Jarak antara ruang $R_{3}$ dan $R_{4}$ adalah 1 , $R_{2}$ dan $R_{3}$ adalah $1, R_{2}$ dan $R_{5}$ adalah $2, R_{2}$ dan $R_{12}$ adalah $1, R_{2}$ dan $R_{8}$ adalah 3 dan seterusnya. Sedangkan jarak antara suatu ruang dengan dirinya sendiri adalah 0. Misalkan akan dipasang sensor deteksi adanya api dengan warna merah pada salah satu ruang. Jika ada api disuatu ruang, maka sensor akan mendeteksi jarak dari ruang adanya api dengan ruang yang dipasang sensor merah. Sebagai contoh, misalkan sensor diletakkan di $R_{2}$. Jika api muncul di $R_{3}$, maka sensor mengidentifikasikan bahwa api muncul dari ruang yang berjarak 1 dari $R_{2}$, dan ruang yang berjarak 1 dari $R_{2}$ ada 4 yaitu $R_{1}, R_{3}, R_{11}$ dan $R_{12}$ sehingga tidak dapat diketahui dengan pasti api berasal dari ruang yang mana. Sebaliknya apabila semua ruang dipasang sensor maka dengan pasti dapat diketahui asal adanya api. Akan tetapi hal ini bukanlah yang diharapkan. Persoalannya adalah minimal berapa banyak sensor yang dibutuhkan dan ruang mana saja yang harus dipasang sensor sehingga apabila muncul api dari ruang manapun akan dapat diketahui dengan tepat sumber adanya api. Dengan demikian kebakaran yang lebih luas dapat dicegah. Berikut adalah analisa yang dilakukan untuk gedung Gambar 2. 


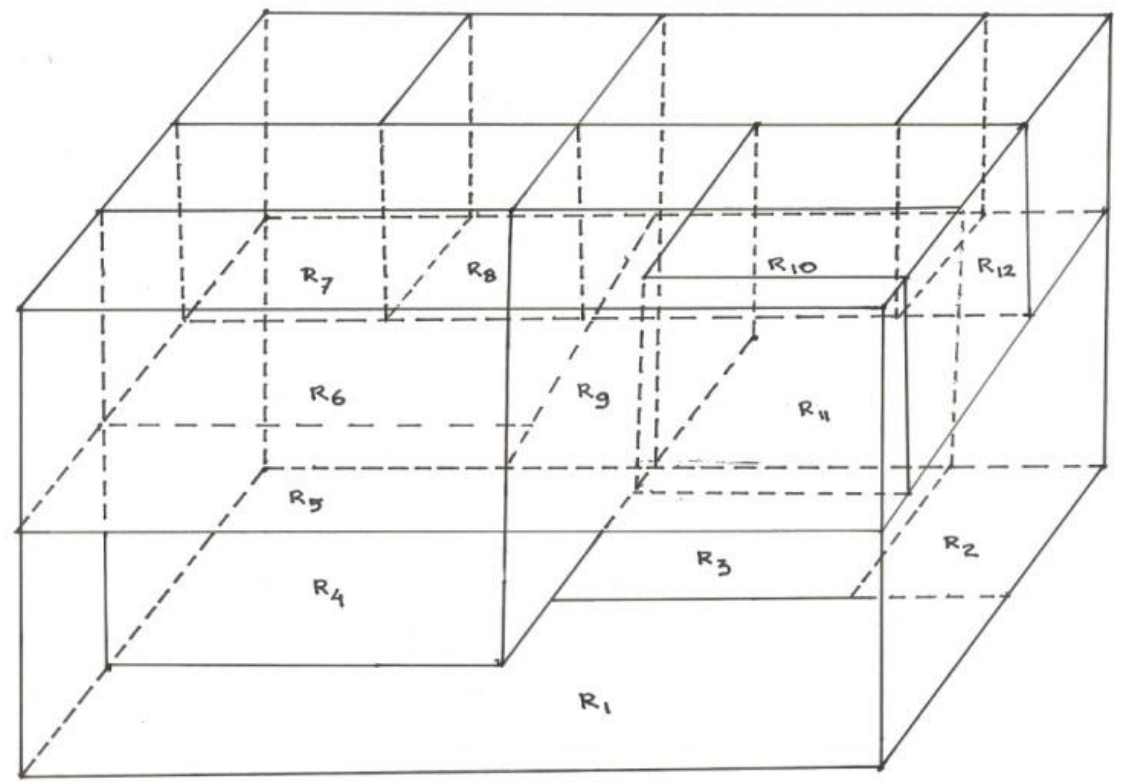

Gambar 2 Sebuah gedung dengan 12 ruangan

Graf yang mewakili Gambar 2 adalah graf terhubung $G$ dengan 12 vertex dan 30 edge seperti yang diperlihatkan pada Gambar 3.

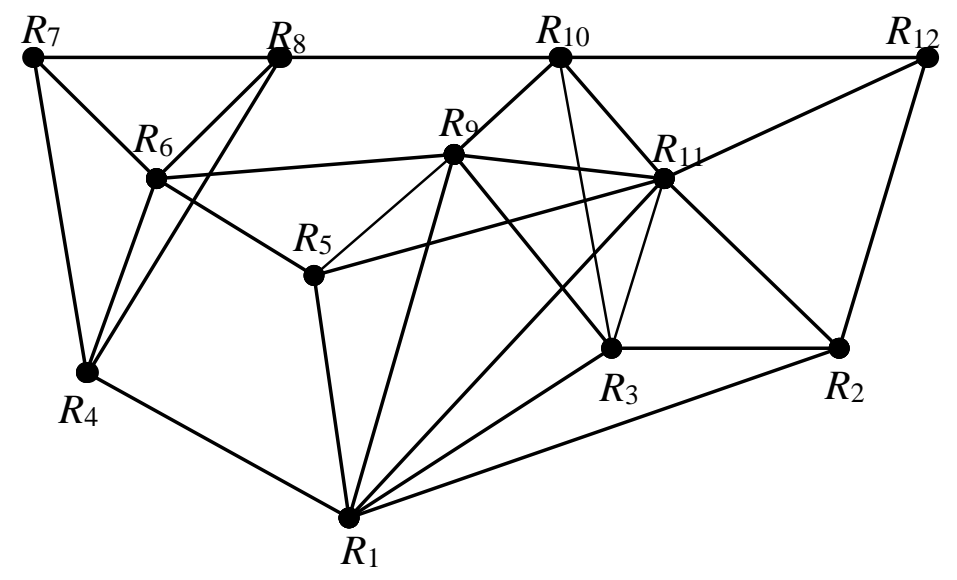

Gambar 3 Representasi graf $G$ Gambar 2

Karena graf $G$ pada Gambar 3 bukan graf Path, maka dimensi metriknya $\geq 2$ [5]. Sehingga penyelidikan himpunan resolving untuk Graf $G$ Gambar 3 dimulai dari himpunan terurut $W$ dengan anggota 2 vertex di $G$. Dalam kasus ini ada sebanyak 66 macam himpunan terurut $W$. Dari penyelidikan yang dilakukan, tidak terdapat himpunan terurut $W$ yang menghasilkan huimpunan resolving, sehingga dimensi metrik graf $G$ Gambar 3 adalah $\neq 2$. Dalam hal ini, sebagai contoh diambil 3 kasus saja. Misalnya diambil $W_{1}=\left(R_{1}, R_{2}\right), W_{2}=\left(R_{2}, R_{3}\right), W_{3}=$ 
$\left(R_{6}, R_{11}\right)$. Representasi vertex-vertex di graf $G$ pada Gambar 3 terhadap $W_{1}, W_{2}, W_{3}$ adalah sebagai berikut :

1. $W_{1}=\left(R_{1}, R_{2}\right)$

Representasi vertex-vertex di graf $G$ terhadap $W_{1}$ adalah $r\left(R_{1} \mid W_{1}\right)=(0,1), r\left(R_{2} \mid W_{1}\right)=$ $(1,0), \quad r\left(R_{3} \mid W_{1}\right)=(1,1), \quad r\left(R_{4} \mid W_{1}\right)=(1,2), \quad r\left(R_{5} \mid W_{1}\right)=(1,2), \quad r\left(R_{6} \mid W_{1}\right)=(2,3)$, $r\left(R_{7} \mid W_{1}\right)=(2,3), \quad r\left(R_{8} \mid W_{1}\right)=(2,3), \quad r\left(R_{9} \mid W_{1}\right)=(1,2), \quad r\left(R_{10} \mid W_{1}\right)=(2,2)$, $r\left(R_{11} \mid W_{1}\right)=(1,1), \quad r\left(R_{12} \mid W_{1}\right)=(2,1)$.

Disini terlihat bahwa $r\left(R_{3} \mid W_{1}\right)=\left(R_{11} \mid W_{1}\right)=(1,1), \quad r\left(R_{4} \mid W_{1}\right)=\left(R_{5} \mid W_{1}\right)=$ $r\left(R_{9} \mid W_{1}\right)=(1,2)$, dan $r\left(R_{6} \mid W_{1}\right)=r\left(R_{7} \mid W_{1}\right)=r\left(R_{8} \mid W_{1}\right)=(2,3)$. Jadi $W_{1}=\left(R_{1}, R_{2}\right)$ bukan himpunan resolving.

2. $W_{2}=\left(R_{2}, R_{3}\right)$

Representasi vertex-vertex di graf $G$ terhadap $W_{2}$ adalah $r\left(R_{1} \mid W_{2}\right)=(1,1), r\left(R_{2} \mid W_{2}\right)=$ $(0,1), \quad r\left(R_{3} \mid W_{2}\right)=(1,0), \quad r\left(R_{4} \mid W_{2}\right)=(2,2), \quad r\left(R_{5} \mid W_{2}\right)=(2,2), \quad r\left(R_{6} \mid W_{2}\right)=(3,2)$, $r\left(R_{7} \mid W_{2}\right)=(3,3), \quad r\left(R_{8} \mid W_{2}\right)=(3,2), \quad r\left(R_{9} \mid W_{2}\right)=(2,1), \quad r\left(R_{10} \mid W_{2}\right)=(2,1)$, $r\left(R_{11} \mid W_{2}\right)=(1,1), \quad r\left(R_{12} \mid W_{2}\right)=(1,2)$.

Disini terlihat bahwa $r\left(R_{1} \mid W_{2}\right)=r\left(R_{11} \mid W_{2}\right)=(1,1), r\left(R_{4} \mid W_{2}\right)=r\left(R_{5} \mid W_{2}\right)=(2,2)$, $r\left(R_{6} \mid W_{2}\right)=r\left(R_{8} \mid W_{2}\right)=(3,2), \quad$ dan $\quad r\left(R_{9} \mid W_{2}\right)=r\left(R_{10} \mid W_{2}\right)=(2,1)$. Jadi $W_{2}=$ $\left(R_{2}, R_{3}\right)$ bukan himpunan resolving.

3. $W_{3}=\left(R_{6}, R_{11}\right)$

Representasi vertex-vertex di graf $G$ terhadap $W_{3}$ adalah $r\left(R_{1} \mid W_{3}\right)=(2,1), r\left(R_{2} \mid W_{3}\right)=$ $(3,1), \quad r\left(R_{3} \mid W_{3}\right)=(2,1), \quad r\left(R_{4} \mid W_{3}\right)=(1,2), \quad r\left(R_{5} \mid W_{3}\right)=(1,1), \quad r\left(R_{6} \mid W_{3}\right)=(0,2)$, $r\left(R_{7} \mid W_{3}\right)=(1,3), \quad r\left(R_{8} \mid W_{3}\right)=(1,2), \quad r\left(R_{9} \mid W_{3}\right)=(1,1), \quad r\left(R_{10} \mid W_{3}\right)=(2,1)$, $r\left(R_{11} \mid W_{3}\right)=(2,0), \quad r\left(R_{12} \mid W_{3}\right)=(3,1)$.

Disini terlihat bahwa $r\left(R_{1} \mid W_{3}\right)=r\left(R_{3} \mid W_{3}\right)=r\left(R_{10} \mid W_{3}\right)=(2,1), \quad r\left(R_{2} \mid W_{3}\right)=$ $r\left(R_{12} \mid W_{3}\right)=(3,1), \quad r\left(R_{4} \mid W_{3}\right)=r\left(R_{8} \mid W_{3}\right)=(1,2), \quad$ dan $\quad r\left(R_{5} \mid W_{3}\right)=r\left(R_{9} \mid W_{3}\right)=$ $(1,1)$. Jadi $W_{3}=\left(R_{6}, R_{11}\right)$ bukan himpunan resolving.

Selanjutnya penyelidikan dilakukan untuk himpunan terurut $W$ dengan anggota 3 vertex di $G$. Dalam kasus ini ada sebanyak 220 macam himpunan terurut $W$. Dari proses perhitungan yang dilakukan, terdapat 14 himpunan resolving untuk graf $G$ pada Gambar 3 yaitu $W_{1}=\left(R_{1}, R_{3}, R_{6}\right)$, $W_{2}=\left(R_{1}, R_{7}, R_{9}\right), \quad W_{3}=\left(R_{1}, R_{9}, R_{12}\right), \quad W_{4}=\left(R_{2}, R_{3}, R_{5}\right), \quad W_{5}=\left(R_{2}, R_{3}, R_{6}\right), \quad W_{6}=$ $\left(R_{2}, R_{3}, R_{9}\right), W_{7}=\left(R_{2}, R_{3}, R_{10}\right), W_{8}=\left(R_{2}, R_{3}, R_{12}\right), W_{9}=\left(R_{2}, R_{5}, R_{12}\right), W_{10}=\left(R_{3}, R_{5}, R_{7}\right)$, $W_{11}=\left(R_{3}, R_{6}, R_{7}\right), W_{12}=\left(R_{3}, R_{6}, R_{11}\right), W_{13}=\left(R_{4}, R_{6}, R_{10}\right), W_{14}=\left(R_{6}, R_{10}, R_{11}\right)$. 
Misalkan dipilih $W_{9}=\left(R_{2}, R_{5}, R_{12}\right)$. Maka representasi vertex-vertex di graf $G$ terhadap $W_{1}$ adalah $\quad r\left(R_{1} \mid W_{9}\right)=(1,1,2), \quad r\left(R_{5} \mid W_{9}\right)=(2,0,2), \quad r\left(R_{9} \mid W_{9}\right)=(2,1,2), \quad r\left(R_{2} \mid W_{9}\right)=(0,2,1)$, $r\left(R_{6} \mid W_{9}\right)=(3,1,3), \quad r\left(R_{10} \mid W_{9}\right)=(2,2,1), \quad r\left(R_{3} \mid W_{9}\right)=(1,2,2), \quad r\left(R_{7} \mid W_{9}\right)=(3,2,3)$, $r\left(R_{11} \mid W_{9}\right)=(1,1,1), \quad r\left(R_{4} \mid W_{9}\right)=(2,2,3), \quad r\left(R_{8} \mid W_{9}\right)=(3,2,2), \quad r\left(R_{12} \mid W_{9}\right)=(1,2,0)$. Karena semua representasi vertex $G$ terhadap $W_{9}$ berbeda, maka $W_{9}=\left(R_{2}, R_{5}, R_{12}\right)$ adalah himpunan resolving. Jadi dimensi graf $G$ adalah 3 . Hal ini berakibat bahwa apabila akan dipasang sensor kebakaran pada gedung Gambar 2, maka minimal dipasang 3 sensor pada gedung tersebut. Pemasangan sensor haruslah pada himpunan resolving. Andaikan yang dipilih adalah $W_{9}=\left(R_{2}, R_{5}, R_{12}\right)$. Misalnya dipasang sensor warna merah di $R_{2}$, sensor warna biru di $R_{5}$, dan sensor warna kuning di $R_{12}$. Apabila muncul api di salah satu ruang gedung tersebut, maka secara tepat dapat ditentukan asal adanya api karena setiap ruang mempunyai representasi yang berbeda terhadap $\left(R_{2}, R_{5}, R_{12}\right)$. Sebagai contoh, misalnya muncul api di $R_{9}$, maka sensor merah mengidentifikasikan api berasal dari ruang yang berjarak 2 terhadap $R_{2}$, sensor biru mengidentifikasikan api berasal dari ruang yang berjarak 1 terhadap $R_{5}$, dan sensor kuning mengidentifikasikan api berasal dari ruang yang berjarak 2 terhadap $R_{12}$, atau secara singkat api berasal dari ruang dengan jarak $(2,1,2)$ dari $\left(R_{2}, R_{5}, R_{12}\right)$. Dan satu-satunya ruang dengan identifikasi seperti ini adalah $R_{9}$. Jadi dengan tepat dapat disimpulkan bahwa api berasal dari $R_{9}$.

Meskipun dimensi metrik graf $G$ pada Gambar 3 adalah 3 sehingga minimal 3 sensor yang harus dipasang di gedung Gambar 2 tersebut, akan tetapi kalau kita tidak tepat memilih 3 ruangan yang dipasang sensor tersebut, maka hal ini akan mengakibatkan kita tidak dapat secara tepat menentukan asal adanya api. Misalnya dipilih ruang yang dipasang sensor adalah $\left(R_{1}, R_{2}, R_{9}\right)$, maka apabila muncul api $R_{3}$, sensor mengidentifikasikan api berasal dari ruang dengan jarak terhadap $\left(R_{1}, R_{2}, R_{9}\right)$ adalah $(1,1,1)$. Disisi lain jarak $R_{11}$ terhadap $\left(R_{1}, R_{2}, R_{9}\right)$ juga $(1,1,1)$. Jadi kita tidak dapat menentukan dengan tepat apakah api berasal dari $R_{3}$ atau $R_{11}$. Demikian pula dengan $R_{7}$ dan $R_{8}$ yang mempunyai jarak yang sama terhadap $\left(R_{1}, R_{2}, R_{9}\right)$ yaitu $(2,3,2)$. Hal ini dikarenakan bahwa $\left(R_{1}, R_{2}, R_{9}\right)$ bukan himpunan resolving dari graf $G$ Gambar 3 diatas. Hal ini dapat diuraikan sebagai berikut :

$W_{n}=\left(R_{1}, R_{2}, R_{9}\right)$, maka representasi vertex-vertex di graf $G$ terhadap $W_{n}$ adalah $r\left(R_{1} \mid W_{n}\right)=(0,1,1), \quad r\left(R_{5} \mid W_{n}\right)=(1,2,1), \quad r\left(R_{9} \mid W_{n}\right)=(1,2,0), \quad r\left(R_{2} \mid W_{n}\right)=(1,0,2)$, $r\left(R_{6} \mid W_{n}\right)=(2,3,1), \quad r\left(R_{10} \mid W_{n}\right)=(2,2,1), \quad r\left(R_{3} \mid W_{n}\right)=(1,1,1) \quad r\left(R_{7} \mid W_{n}\right)=(2,3,2)$, $r\left(R_{11} \mid W_{n}\right)=(1,1,1), \quad r\left(R_{4} \mid W_{n}\right)=(1,2,2), \quad r\left(R_{8} \mid W_{n}\right)=(2,3,2) \quad r\left(R_{12} \mid W_{n}\right)=(2,1,2) . \quad$ Karena 
$r\left(R_{3} \mid W_{n}\right)=r\left(R_{11} \mid W_{n}\right)=(1,1,1) \quad$ dan $\quad r\left(R_{7} \mid W_{n}\right)=r\left(R_{8} \mid W_{n}\right)=(2,3,2)$, maka $W_{n}=\left(R_{1}, R_{2}, R_{9}\right)$ bukan himpunan resolving.

\section{Simpulan}

Dimensi metrik suatu graf yang diperoleh dari denah ruang suatu gedung dapat direpresentasikan sebagai minimal banyaknya sensor api kebakaran yang harus dipasang pada gedung tersebut, sedangkan himpunan resolving dengan kardinalitas minimum menunjukkan ruangan mana saja yang harus dipasang sensor tersebut. Dari analisa yang dilakukan, sensor kebakaran yang harus dipasang di gedung hanya di tiga ruangan saja.

\section{DAFTAR PUSTAKA}

[1] S. Allesina and J. M. Levine, "A competitive network theory of species diversity," Proc. Natl. Acad. Sci. U. S. A., 2011.

[2] M. B. Hu, R. Jiang, Y. H. Wu, W. X. Wang, and Q. S. Wu, "Urban traffic from the perspective of dual graph," Eur. Phys. J. B, 2008.

[3] Peter J. Slater, "Leaves of Trees," in Proceeding of International Conference On Research, Implementation And Education Of Mathematics And SciencesProceeding of the 6th Southeastern Conference on Combinatorics, Graph Theory, and Computing, Congressus Numerantium, 1975, pp. 549-559.

[4] F. Harary and R. A. Melter, "On the Metric Dimension of a Graph," Ars Comb., vol. 2, pp. 191-195, 1976.

[5] G. Chartrand, L. Eroh, M. A. Johnson, and O. R. Oellermann, "Resolvability in graphs and the metric dimension of a graph," Discret. Appl. Math., 2000.

[6] Rinurwati, Slamin, and H. Suprajitno, "On (local) metric dimension of graphs with m pendant points,” J. Phys. Conf. Ser., vol. 855, no. 1, p. 12035, 2017.

[7] S. Wahyudi, S. Sumarno, and S. Sanjaya, "Dimensi metrik pengembangan graf kincir pola K1 + mK3,” Limits J. Math. Its Appl., vol. 8, no. 2, p. 17, Nov. 2011.

[8] G. Chartrand and P. Zhang, "The theory and applications of resolvability in graphs: A survey," Congr. Numer., vol. 160, 2003. 